\title{
İlkokul ve Ortaokullarda Çevre Eğitimi Verecek Olan Öğretmen Adaylarında Çevre Sorunlarına Yönelik Davranışların Araştırıl- $\operatorname{masl}^{1}$
}

\section{Investigation of Behaviors Towards Environmental Problems in Teach- er Candidates Who Will Give Environmental Education at Primary and Secondary Schools}

\author{
DOI $=\underline{10.17556 / \text { jef. }_{.} 93507}$ \\ Mustafa KIŞOĞLU ${ }^{* *}$, Tahsin YILDIRIM
SÜLÜN ${ }^{* * * * * * *}$
}

\section{Özet}

Yapılan bu çalışmanın amacı mezun olduklarında çevre eğitimi verecek olan fen bilgisi, sınıf ve sosyal bilgiler öğretmen adaylarının sorumlu çevresel davranışlarının farklı değişkenler açısından incelenmesidir. Tarama modeliyle gerçekleştirilen betimsel bir araştırma olan çalışmanın örneklemini ülkemizin İç Anadolu Bölgesinde bulunan bir üniversitenin fen bilgisi, sınıf ve sosyal bilgiler öğretmenliği anabilim dalı birinci ve dördüncü sınıfında okuyan 344 öğretmen adayı oluşturmaktadır. Veri toplama aracı olarak Güven ve Aydoğdu (2012) tarafindan geliştirilen 40 maddelik "Çevre Sorunlarına Yönelik Davranış Ölçeği" kullanılmıştır. Çalışma sonucunda öğretmen adaylarının çevresel davranış ölçeği puan ortalamalarının, ölçekten alınabilecek ortalama puanın üzerinde olduğu bulunmuştur. Ayrıca çalışma sonunda öğretmen adaylarının çevresel davranışlarının adayların cinsiyetlerine, çevre kuruluşlarına üyeliklerine ve öğrenim gördükleri anabilim dallarına göre farklılaşmadığı belirlenmiştir. Resmi kuruluşlar tarafindan düzenlenen çevresel etkinliklere katılan öğretmen adaylarının davranış ölçeği puanları katılmayanlara göre istatistiksel olarak daha yüksektir. Birinci ve dördüncü sınıfta okuyan öğretmen adaylarının çevresel davranış ölçeği puanları arasında ise dördüncü sınıfta okuyan öğretmen adaylarının lehine anlamlı bir farklılık vardır. Tespit edilen bu farklılık fen bilgisi öğretmenliği anabilim dalında anlamlı iken diğer iki anabilim dalında anlamlı değildir.

\footnotetext{
1 Bu çalıșmanın özeti 08-10 Ekim 2015 tarihleri arasında Nevşehir'de düzenlenen III Uluslar arası İlkokul Eğitimi Konferansında sözlü bildiri olarak sunulmuştur.

** Yrd. Doç. Dr., Aksaray Üniversitesi Eğitim Fakültesi, mkisoglu @ hotmail.com

*** Yrd. Doç. Dr., Aksaray Üniversitesi Eğitim Fakültesi, tahsinyildirim@msn.com

***** Yrd. Doç. Dr., Kastamonu Üniversitesi Eğitim Fakültesi, msalman1917@ hotmail.com

***** Prof. Dr., Erzincan Üniversitesi Eğitim Fakültesi, asulun617@ hotmail.com
} 
$\underline{\text { M.Kışoğlu,T.Yıldırım... /Ë̈ Ĕ̆itim Fakültesi Dergisi, 18-1(2016),299-318 }}$

Anahtar sözcük: Öğretmen adayı, çevre sorunlarına yönelik davranış, çevre eğitimi, Türkiye

\begin{abstract}
This study was carried out in order to examine different variables in terms of the responsible environment behaviors of science and classroom teacher and social studies preservice teachers that will give environment education when they graduate. The sample of the study that is a descriptive study was performed with scanning model constituting 344 preservice teachers studying in the first and fourth classes of the university located in the central of Anatolia. "Environmental problems Behavior Scale" with 40 items was used as a data collection tool developed by Güven and Aydoğdu (2012). The average of the behavior environment behavior scale was found above the average score as the result of the study. Also at the end of the study, it has been determined that the gender of the preservice teachers, the membership of an environmental organization of the teacher candidates, the department of the preservice teachers studying did not differentiate. The behavior scale scores of the teacher candidates who participated in environmental activities are statistically higher than the teacher candidates do not participate in. Between the environmental scale scores of the teacher candidates studying in the first and fourth class, there is a significant difference in favor of the preservice teachers studying in the fourth class. While this difference detected in the department of science is meaningful, in the other two departments are not meaningful.
\end{abstract}

Keywords: Teacher candidates, behavior towards environmental problems, environmental education, Turkey

\title{
Giriş
}

İçinde yaşadığımız yüzyıl çevre sorunlarının etkilerinin artarak hissedilmeye başlandığı bir dönem haline gelmiştir. Bu sorunların odağında insan faktörünün olduğunu belirten Gül (2013), modern insanın zaman içinde değişen doğayla ilgili anlayış ve bakış açısının bugünkü çevre sorunlarının temelini oluşturduğunu ifade etmiştir. Özellikle sanayi devrimiyle birlikte insan-doğa ilişkilerinde doğa merkezli anlayış yerine insan merkezli anlayış egemen olmuştur. Bu yeni anlayışta merkezde insan yer alır ve insan-doğa ilişkilerinde ölçü insan ve onun ihtiyaçlarıdır (Gül, 2013). İnsanların ihtiyaçlarını karşılamak için kendi çıkarları doğrultusunda yapmış oldukları davranışlar çevre üzerinde bir baskı oluşturmuş (Pradhan et al., 2015) ve bunun sonucunda bugün karşı karşıya olduğumuz çevre sorunları ortaya çıkmıştır.

Küresel ısınma, hava kirliliği, gürültü ve biyoçeşitliliğin azalmas1 gibi sürdürülebilirliği tehdit eden çevre problemlerinin temel nedeni insan davranışlarıdır (Vlek and Steg, 2007). Swim, Clayton 
and Howard (2011) yapmış oldukları araştırmada nüfus artışına paralel olarak insanların artan tüketim davranışlarının doğal çevreye negatif yönde bir etkisi olduğunu ve küresel iklim değişikliğini hızlandırdığını belirtmişlerdir. İnsan davranışlarının çevreye olumsuz etkilerinin azaltılması bireylerin mevcut davranışlarını değiştirmekle mümkündür (Steg and Vlek, 2009). Bireylerin çevreye zarar veren davranışlarının değiştirilmesi ve bireylere çevreye duyarlı davranışların kazandırılması etkili bir çevre eğitimi ile sağlanabilir. Çevre eğitimi araştırmacıları tarafından kabul edilen genel görüşe göre çevre eğitimin temel amacı bireylerin davranışlarını etkileyerek onlara olumlu ve kalıcı davranışlar kazandırmak ve çevre sorunlarının çözümünde aktif rol üstlenen bireyleri yetiştirmektir (Şimşekli, 2004; Eilam and Trop, 2012). Dolayısıyla çevresel davranışları olumlu yönde etkileyebilen çevre eğitimi, çevre sorunlarının çözümünün kilit anahtarı olarak görülmektedir (Disinger, 1982).

"Aile, okul ve yakın çevre, çevre eğitimini sağlamada üç temel unsurdur. Çevre eğitimi çocuğa ailede başlatılır, yakın çevresi ve okulda da sürdürülür.” (Bener ve Babaoğul, 2008:5). Çevre eğitimi her ne kadar ailede başlasa da, bireylere olumlu çevresel davranışların kazandırılacağı en etkili yerler örgün eğitim kurumları olan okullardır. Erökten ve Durkan (2010)'ın çevre eğitimi dersinin sınıf öğretmeni adaylarının çevreye karşı tutum ve davranışları üzerine olan etkisini inceledikleri çalışmalarında çevre eğitiminin öğretmen adaylarının çevreye karşı tutum ve davranışlarında olumlu yönde değişmelere neden olduğu ifade edilmiştir. Uzun ve Sağlam (2007) tarafından ortaöğretim öğrencileriyle yapılan bir diğer çalışma sonunda da "Çevre ve İnsan" dersini alan ortaöğretim öğrencilerinin çevresel davranış puanı ortalamalarının dersi almayan öğrencilerden daha yüksek olduğu belirlenmiştir.

Temel hedefi çevresel bilgiyi artırarak çevreye yönelik davranışları değiştirmek olan çevre eğitim programlarında (Pooley and O'conner, 2000), programın uygulayıcıları olan öğretmenlere önemli görevler düşmektedir. Kimaryo (2011)'ya göre çevre okuryazarı bireylerin oluşturulmasında çevre eğitimi programlarının uygulayıcıları olan öğretmenler önemli bir role sahiptir. Çevre eğitimi programını uygulamanın yanı sıra öğrencileri için rol model olan öğretmenlerin çevreye yönelik olumlu davranışları öğrencilerin davranışlarını da olumlu yönde etkileyecektir (Timur v.d., 2013). Bu nedenle öğretmen 
yetiştiren kurumlarda okuyan öğretmen adaylarının çevre sorunlarına yönelik davranışlarının belirlenerek ortaya çıkan sonuçlara göre gerekli önlemlerin alınması çevre sorunlarının giderilmesi ve önlenmesi açısından oldukça önemlidir (Güven ve Aydoğdu, 2012).

Goldman et al. (2006), İsrail'de öğretmen yetiştiren 3 büyük kurumdaki 765 öğretmen adayının çevresel davranışlarını belirlemeyi amaçladıkları çalışmalarında öğretmen adaylarının yüksek seviyede sorumluluk gerektiren çevresel davranışları sergileme düzeylerinin sınırlı olduğunu ifade etmişlerdir. Pe'er et al. (2007) ise İsrail'de öğretmen yetiştiren kurumlarda öğrenim gören birinci sınıf öğrencilerinin çevresel bilgi, tutum ve davranışlarını inceledikleri çalışma sonucunda öğretmen adaylarının çevresel bilgi düzeylerinin sınırlı olduğu, çevresel davranış düzeylerinin ise orta seviyede olduğu tespit edilmiştir. Altınöz (2010) tarafından yapılan ve fen bilgisi öğretmenliği anabilim dalı 1., 2., 3. ve 4. Sınıfta öğrenim gören 271 öğretmen adayının çevre okuryazarlık düzeylerinin çevre okuryazarlığ 1 bileşenlerine (bilgi, tutum, davranış ve algı) göre incelenmesinin amaçlandığı çalışma sonucunda öğretmen adaylarının kısmen yüksek çevresel tutuma ve orta seviyede bir çevresel algıya sahip oldukları belirlenmiştir. Bununla birlikte çalışmada öğretmen adaylarının çevresel bilgi ve davranışlarının düşük seviyede olduğu tespit edilmiştir. Çimen v.d. (2011)'nin 120 biyoloji öğretmeni adayının çevreye duyarlı davranışlarını incelediği bir diğer çalışma sonunda ise biyoloji öğretmeni adaylarının çevreye duyarlı davranışlarının orta seviye ile yüksek seviye arasında olduğu ifade edilmiştir. Ayrıca konuyla ilgili alan yazında öğretmen adaylarının çevresel davranışlarına etkisi olabilecek faktörlerle ilgili yapılan çalışmalar incelendiğinde, öğretmen adaylarının çevresel davranışlarının öğrenim gördükleri sınıf (birinci ve dördüncü sınıf) düzeylerine (Akıllı ve Yurtcan, 2009; Çimen v.d., 2011), anabilim dallarına (Timur v.d., 2013), çevresel kuruluşlara üye olup olmamalarına (Gürbüz ve Çakmak, 2012; Koç ve Karatekin, 2013), bilimsel çevresel etkinliklere katılımları (Keleş v.d., 2010) ile cinsiyet (Timur v.d., 2012; Malhotra and Chabra, 2014), babanın eğitim düzeyi (Sadık ve Çakan, 2010) ve yerleşim yeri (Goldman, Yavetz and Pe'er, 2006) gibi demografik özelliklerine göre farklılaştı̆̆ görülmektedir.

Ülkemizde çevre eğitimine ilkokul ve ortaokullarda fen bilimleri, hayat bilgisi ve sosyal bilgiler dersi öğretim programları içeris- 
inde yer verilmektedir (Karatekin, 2013). Dolayısıyla öğretmen olarak göreve başladıklarında derslerinde çevre eğitimi verecek ve davranışlarıyla öğrencilerine örnek olacak fen bilgisi, sınıf ve sosyal bilgiler öğretmen adaylarının çevresel davranışları ile davranışlarına etki eden faktörlerin belirlenmesi çevre eğitiminin etkililiğinin artırılması açısından oldukça önemlidir. Bu nedenle yapılan bu çalışmada fen bilgisi, sınıf ve sosyal bilgiler öğretmen adaylarının çevre sorunlarına yönelik davranış düzeylerinin farklı değişkenler açısından incelenmesi amaçlanmıştır.

\section{Model}

\section{Yöntem}

Çalışma tarama modeliyle gerçekleştirilen betimsel bir çalışmadır. Yapılan araştırmada tarama modelinin kullanılmasının nedeni tarama modelinin geçmişte veya halihazırdaki mevcut durumu, herhangi bir etki veya değişikliğe maruz bırakmadan, olduğu şekliyle betimlemeyi amaçlayan bir model olmasıdır (Karasar, 1994).

\section{Evren ve Örneklem}

Çalışmanın evrenini 2014-2015 eğitim-öğretim yılının bahar döneminde Türkiye'deki eğitim fakültelerinin birinci ve dördüncü sınıfında öğrenim görmekte olan öğretmen adayları oluşturmaktadır. Çalışmanın örneklemini ise ülkemizin İç Anadolu Bölgesinde yer alan bir üniversitenin eğitim fakültesinin fen bilgisi, sınıf ve sosyal bilgiler öğretmenliği anabilim dallarının birinci ve dördüncü sınıflarında öğrenim gören 344 öğretmen adayı oluşturmaktadır. Örneklemin birinci ve dördüncü sınıf öğrencileri olarak belirlenmesinin nedeni öğretmen adaylarının öğrenimlerine başladıklarında (çevreyle ilgili herhangi bir ders almadan) ve mezun olduklarında (çevreyle ilgili dersleri aldıktan sonra) çevreye duyarlı davranışlarında herhangi bir değişimin olup olmadığının belirlenmesidir. Ayrıca örneklemi fen bilgisi, sınıf ve sosyal bilgiler öğretmenliği anabilim dalı öğrencilerinin oluşturmasının nedeni ise ilkokul ve ortaokullarda çevreyle ilgili olan konulara fen bilimleri, hayat bilgisi ve sosyal bilgiler ögretim programlarında yer verilmesidir.

\section{Veri Toplama Aracı}

Çalışmanın verileri iki bölümden oluşan bir anket aracılığıyla toplanmıştır. Anketin birinci bölümünde öğretmen adaylarının cinsiyetlerini, öğrenim gördükleri anabilim dallarını ve sınıflarını, herhangi bir çevre kuruluşuna üye olup olmadıklarını ve resmi ku- 
rumlar tarafindan düzenlenen herhangi bir çevresel etkinliğe (bilim kampı, doğa eğitimi gibi) katılıp katılmadıklarını belirlemeye yönelik sorular yer almaktadir.

Anketin ikinci bölümünde ise Güven ve Aydoğdu (2012) tarafından geliştirilen 40 maddelik "Çevre Sorunlarına Yönelik Davranış Ölçeği" kullanılmıştır. Altı faktörlü ve üçlü likert tipinde (katılmıyorum, yansızım, katılıyorum) hazırlanan davranış ölçeğinde yer alan maddeler Bloom taksonomisindeki psikomotor alan basamakları dikkate alınarak oluşturulmuştur. Ölçeğin geliştirilmesi aşamasında Güven ve Aydoğdu (2012) tarafından yapılan istatistiksel analizler neticesinde elde edilen ve ölçekte yer alan 40 maddenin psikomotor alan basamaklarına göre dağılımı, psikomotor alan isimleri ve faktörlerin güvenirlik katsayıları (Cronbach Alpha) Tablo 1'de özetlenmiştir. Kullanılan ölçeğin bu çalışma için hesaplanan güvenirlik katsayısı ise 0,82 ' dir.

Tablo.1. "Çevre Sorunlarına Yönelik Davranış Ölçeği”ne ait psikomotor alan basamakları, soru sayıları ve faktörlerin güvenirlik katsayıları (Güven ve Aydoğdu, 2012)

\begin{tabular}{lcc}
\hline $\begin{array}{c}\text { Psikomotor Alan } \\
\text { Basamakları }\end{array}$ & $\begin{array}{c}\text { Soru } \\
\text { Sayıları }\end{array}$ & $\begin{array}{c}\text { Güvenirlik } \\
\text { Katsayıları }\end{array}$ \\
\hline Algılama & 4 & 0,79 \\
Kurulma & 8 & 0,98 \\
Kılavuzlama & 6 & 0,95 \\
Beceriye dönüştürme & 10 & 0,90 \\
Duruma uydurma & 5 & 0,85 \\
Yaratma & 7 & 0,79 \\
\hline Toplam & 40 & 0,85 \\
\hline Verilerin Analizi & \\
Çalışmanın verileri kodlanırken ölçekteki maddelere katılma- \\
ŏgretmen adaylarının cevapları 1, yansız olduğunu belirtenlerin \\
ları 2, katıldığını ifade eden öğretmen adaylarının cevapları ise 3 \\
kodlanmıştır. Ölçekte olumsuzluk ifade eden maddeler ko- \\
ken ters çevrilmiştir. Veriler bağımsı gruplar t testi ve tek yönlü \\
a kullanılarak SPSS 15.0 istatistik programında analiz edilmiştir. \\
tiksel değerlendirmelerde ise anlamlılık düzeyi (p) 0,05 olarak \\
1ştır.
\end{tabular}




\section{Bulgular}

Çalışmaya katılan fen bilgisi, sınıf ve sosyal bilgiler öğretmen adaylarının "Çevre Sorunlarına Yönelik Davranış Ölçeğii” puanlarına ait istatistiksel bulgular Tablo.2’de özetlenmiştir.

Tablo.2. Öğretmen adaylarının "Çevre Sorunlarına Yönelik Davranış Ölçeği” puanlarına ait istatistiksel analiz sonuçları

\begin{tabular}{cccccc}
\hline Davranış Ölçeği & $\mathbf{N}$ & Ort. & S.S. & Minimum & Maksimum \\
\hline Ölçek Puanı & 344 & 92,01 & 10,29 & 60 & 116 \\
\hline
\end{tabular}

Tablo 2. İncelendiğinde öğretmen adaylarının ölçekten almış oldukları en düşük puanın 60, en yüksek puanın 116 ve puan ortalamasının ise 92,01 olduğu görülmektedir. Ayrıca öğretmen adaylarının ölçekten elde etmiş oldukları puanların standart sapması 10,29 olarak hesaplanmıştır. Bu sonuca göre öğretmen adaylarının davranış ölçeği puanlarının ölçekten alınabilecek ortalama puanın üzerinde olduğu anlaşılmaktadır.

Öğretmen adaylarının davranış ölçeği puanlarında cinsiyetlerine göre bir farklılık olup olmadığının belirlenmesine yönelik yapılan bağımsız gruplar t-testi analizi sonuçları Tablo.3'te özetlenmiştir.

Tablo.3. Öğretmen adaylarının "Çevre Sorunlarına Yönelik Davranış Ölçeği” puanlarına ait cinsiyet analizi sonuçları

\begin{tabular}{ccccccc}
\hline Cinsiyet & N & Ort. & S.S. & S.D. & t & p \\
\hline Bayan & 239 & 92,38 & 9,74 & \multirow{2}{*}{342} & \multirow{2}{*}{967} & \multirow{2}{*}{, 335} \\
\hline Erkek & 105 & 91,14 & 11,47 & & & \\
\hline
\end{tabular}

Tablo 3'e göre bayan öğretmen adaylarının davranış ölçeği puan ortalamasının $(X=92,38)$, erkek öğretmen adaylarının davranış ölçeği puan ortalamasından $(X=91,14)$ yüksek olmakla beraber adayların ölçek puanları arasında cinsiyetlerine göre istatistiksel olarak anlamlı bir farklılığın olmadığı görülmektedir $(\mathrm{p}>0,05)$.

Öğretmen adaylarının çevresel kuruluşlara üyeliklerinin çevresel davranışları üzerinde etkisinin olup olmadığını belirlemek amacıyla yapılan bağımsız gruplar t-testi analizi sonuçları Tablo.4'te verilmiştir. 
M.Kışoğlu,T.Yıldırım... /Ë̈ Ĕ̆itim Fakülttesi Dergisi, 18-1(2016),299-318

Tablo.4. Öğretmen adaylarının "Çevre Sorunlarına Yönelik Davranış Ölçeği” puanlarına ait çevresel kuruluşlara üyelik analizi sonuçları

\begin{tabular}{lcccccc}
\hline \multicolumn{1}{c}{ Üyelik } & $\mathbf{N}$ & Ort. & S.S. & S.D. & t & p \\
\hline Üye & 20 & 94,25 & 10,83 & \multirow{2}{*}{342} & \multirow{2}{*}{1,005} & \multirow{2}{*}{316} \\
\hline Üye değil & 324 & 91,87 & 10,26 & & & \\
\hline
\end{tabular}

Tablo incelendiğinde herhangi bir çevre kuruluşuna üye olan öğretmen adaylarının sayısının $(N=20)$ üye olmayanlardan $(N=324)$ oldukça düşük olduğu görülmektedir. Buna rağmen çevre kuruluşuna üyeliği bulunan öğretmen adaylarının ölçek puanı ortalaması $(X=94,25)$, üyeliği bulunmayan öğretmen adaylarının ölçek puanı ortalamasından $(X=91,87)$ daha yüksektir. Farkın anlamlı olup olmadığına yönelik olarak yapılan t-testi analizi sonucu ise çevre kuruluşuna üye olan ve olmayan öğretmen adaylarının çevresel davranış puan ortalamaları arasında istatistiksel olarak anlamlı bir farklılığın olmadığını göstermektedir ( $\mathrm{p}>0,05)$.

Resmi kurumlar tarafindan düzenlenen çevresel etkinliklere katılan ve katılmayan öğretmen adaylarının çevresel davranış ölçeği puanları arasındaki farklılığın belirlenmesi amacıyla yapılan bağımsız gruplar t-testi analizi sonuçları Tablo 5 'te özetlenmiştir.

Tablo.5. Öğretmen adaylarının "Çevre Sorunlarına Yönelik Davranış Ölçeği” puanlarına ait çevresel etkinliklere katılım analizi sonuçları

\begin{tabular}{lcccccc}
\hline $\begin{array}{c}\text { Etkinliğe } \\
\text { Katılım }\end{array}$ & $\mathbf{N}$ & Ort. & S.S. & S.D. & t & p \\
\hline Katılan & 80 & 93,99 & 9,45 & 342 & 1,974 &, $049^{*}$ \\
\hline Katılmayan & 264 & 91,41 & 10,48 & & & \\
\hline
\end{tabular}

Tablo incelendiğinde resmi kurumlar tarafından düzenlenen çevresel etkinliklere katılan öğretmen adaylarının sayısının $(N=80)$, katılmayan adayların sayısından oldukça düşük olduğu $(N=264)$ görülmektedir. Buna rağmen resmi kurumlar tarafından düzenlenen çevresel etkinliklere katılan öğretmen adaylarının ölçek puanı ortalamaları $(X=93,99)$, katılmayan öğretmen adaylarının ölçek puanı ortalamalarından $(X=91,41)$ istatistiksel olarak daha yüksektir $(\mathrm{p}<0,05)$.

Öğretmen adaylarının davranış ölçeği puanlarının öğrenim gördükleri anabilim dalı analizi sonuçları Tablo.6' da verilmiştir. 
Tablo.6. Öğretmen adaylarının "Çevre Sorunlarına Yönelik Davranış Ölçeği”" puanlarına ait anabilim dalı analizi sonuçlarına ait betimsel bulgular

\begin{tabular}{lccc}
\hline \multicolumn{1}{c}{ Anabilim Dalı } & N & Ort. & S.S. \\
\hline Fen Bilgisi Öğrt. & 84 & 93,48 & 9,81 \\
\hline Sinıf Öğrt. & 146 & 91,81 & 10,28 \\
\hline Sosyal Bilgiler Öğrt. & 114 & 91,18 & 10,63 \\
\hline
\end{tabular}

Tablo incelendiğinde fen bilgisi öğretmenliği anabilim dalında okuyan öğretmen adaylarının ölçek puanları ortalamasının $(X=93,48)$ en yüksek olduğu, sosyal bilgiler öğretmenliği anabilim dalı öğrencilerinin ölçek puanları ortalamasının $(X=91,18)$ ise en düşük olduğu görülmektedir.

Farklı anabilim dallarında (fen bilgisi, sınıf ve sosyal bilgiler öğretmenliği) okuyan öğretmen adaylarının davranış ölçeği puanları arasında herhangi bir farklılığın olup olmadığının belirlenmesine yönelik olarak yapılan tek yönlü varyans analizi sonuçları ise Tablo.7'de verilmiştir.

Tablo.7. Öğretmen adaylarının "Çevre Sorunlarına Yönelik Davranış Ölçeği” puanlarının anabilim dalı analizine ait Tek Yönlü Varyans Analizi Sonuçları

\begin{tabular}{lccccc}
\hline $\begin{array}{c}\text { Varyansın } \\
\text { Kaynağı }\end{array}$ & $\begin{array}{c}\text { Kareler } \\
\text { Toplamı }\end{array}$ & SD & $\begin{array}{c}\text { Kareler } \\
\text { Ortalaması }\end{array}$ & F & p \\
\hline Gruplar arası & 265,915 & 2 & 132,957 & 1,257 &, 286 \\
Gruplar içi & 36082,074 & 341 & 105,813 & & \\
Toplam & 36347,988 & 343 & & & \\
\hline
\end{tabular}

Tablo.7'de özetlenen analiz sonuçlarına göre öğretmen adaylarının davranış ölçeğinden almış oldukları puan ortalamalarının öğrenim gördükleri anabilim dallarına göre farklılaşmamaktadır $(\mathrm{p}>0,05)$.

Birinci ve dördüncü sinıfta öğrenim gören öğretmen adaylarının davranış ölçeğinden elde ettikleri puanların ortalamaları arasında anlamlı bir farklılık olup olmadığı bağımsız gruplar t-testi ile analiz edilmiş ve bulgular Tablo.8'de özetlenmiştir.

Tablo.8. Öğretmen adaylarının "Çevre Sorunlarına Yönelik Davranış Ölçeği” puanlarına ait öğrenim gördükleri sınıf analizi sonuçları 
M.Kışoğlu,T.Yıldırım... /EÜ Ĕ̆itim Fakültesi Dergisi, 18-1(2016),299-318

\begin{tabular}{lcccccc}
\hline \multicolumn{1}{c}{ Sınıf } & N & Ort. & S.S. & S.D. & t & p \\
\hline Birinci sınıf & 156 & 90,28 & 10,97 & \multirow{2}{*}{342} & $-2,869$ &, $004^{*}$ \\
\hline Dördüncü sınıf & 188 & 93,44 & 9,49 & & & \\
\hline
\end{tabular}

Tabloya göre birinci sinıfta öğrenim gören öğretmen adaylarının davranış ölçeği puan ortalaması $X=90,28$, dördüncü sınıfta okuyan öğretmen adaylarının puan ortalaması $X=93,44$ olup birinci ve dördüncü sınıfta öğrenim gören öğretmen adaylarının davranış ölçeği puanları arasında dördüncü sınıfta okuyan öğretmen adaylarının lehine istatistiksel olarak anlamlı bir farklılık olduğu anlaşılmaktadır $(\mathrm{p}<0,05)$.

Birinci ve dördüncü sınıfta okuyan öğretmen adaylarının davranış ölçeği puanları arasında belirlenen farkın anabilim dallarına ait analiz sonuçları ise Tablo.9'da özetlenmiştir.

Tablo.9. Öğretmen adaylarının "Çevre Sorunlarına Yönelik Davranış Ölçeği” puanlarının öğrenim gördükleri sınıflara göre anabilim dalı analizi sonuçları

\begin{tabular}{clcccccc}
\hline Anabilim Dalı & \multicolumn{1}{c}{ Sınıf } & N & Ort. & S.S. & SD & t & p \\
\hline \multirow{2}{*}{ Fen Bilgisi Öğrt. } & Birinci sınıf & 43 & 91,32 & 9,98 & 82 & $-2,075$ &, $041^{*}$ \\
& Dördüncü sınıf & 41 & 95,71 & 9,23 & & & \\
\hline \multirow{2}{*}{ Sınıf Öğrt. } & Birinci sınıf & 60 & 90,13 & 11,83 & 144 & $-1,575$ &, 118 \\
& Dördüncü sınıf & 86 & 92,98 & 8,93 & & & \\
\hline \multirow{2}{*}{ Sosyal Bilgiler Öğrt. } & Birinci sınıf & 53 & 89,57 & 10,87 & 112 & $-1,516$ &, 132 \\
& Dördüncü sınıf & 61 & 92,57 & 10,30 & & & \\
\hline
\end{tabular}

Tablo incelendiğinde her üç anabilim dalının dördüncü sınıfında öğrenim gören öğretmen adaylarının davranış ölçeği puan ortalamalarının, birinci sınıfta öğrenim gören öğretmen adaylarının puan ortalamalarından yüksek olduğu görülmektedir. Ancak yalnızca fen bilgisi öğretmenliği anabilim dalı dördüncü sınıfında okuyan öğretmen adaylarının davranış ölçeği puan ortalamalarındaki artış istatistiksel olarak anlamlıdır $(\mathrm{p}<0,05)$. Sinıf öğretmenliği ve sosyal bilgiler öğretmenliği anabilim dalı dördüncü sınıfında okuyan öğretmen adaylarının davranış ölçeği puanlarındaki artış ise istatistiksel olarak anlamlı değildir $(\mathrm{p}>0,05)$. 


\section{Sonuç ve Tartışma}

Çevre eğitimi iklim değişikliğii, su kıtlığı, yeryüzünün bozulması ile ekosistem ve türlerin azalması gibi çevre sorunlarının çözümü ile ilgili bireylerde davranış gelişimi oluşturmayı amaçlayan bir öğretme ve öğrenme sürecidir (Kanyimba, 2014). Bu sürecin yöneticileri olan öğretmenler ise bireylerde davranış değişikliği oluşturmada önemli bir role sahiptir (Said et al., 2003). Bu nedenle ileride öğretmen olup öğrencilerde sorumlu çevresel davranışları oluşturmaya çalışacak olan öğretmen adaylarının çevresel davranışlarının belirlenmesi, bu davranışların hizmet öncesi dönemde şekillendirilmesi için oldukça önemlidir. Mezun olduklarında ilkokul ve ortaokullarda çevre eğitimi verecek olan fen bilgisi, sınıf ve sosyal bilgiler öğretmen adaylarının sorumlu çevresel davranışlarını farklı değişkenler açısından incelemeyi amaçlayan çalışmanın sonucunda öğretmen adaylarının davranış ölçeğinden almış oldukları puan ortalamasının, ölçekten alınabilecek ortalama puanının üzerinde olduğu belirlenmiştir (Tablo.2). Elde edilen bu sonuç Çimen v.d. (2011)'nin biyoloji öğretmeni adaylarının çevreye duyarlı davranışlarının orta düzey ile yüksek düzey arasında olduğunu ifade ettiği araştırma bulgusuyla örtüşmektedir. Araştırma neticesinde böyle bir sonucun ortaya çıkmasında, öğretmen adaylarının hem artan yaşlarının hem de öğrenim hayatları boyunca almış oldukları çevreyle doğrudan ilgili olan veya içerisinde çevreyle ilgili konuların yer aldığ 1 derslerin etkili olabileceği düşünülmektedir. Willuweit (2009), Abu Dhabi'deki insanların çevresel davranışlarını incelediği çalışmasında yaşça büyük olan bireylerin çevreye duyarlı davranışları sergileme düzeylerinin yaşı küçük olanlara göre daha yüksek olduğunu belirtmiştir. Erökten ve Durkan (2010)'ın sınıf öğretmenliği öğrencilerinin çevre eğitimi dersini almadan önce ve aldıktan sonra çevreye karşı tutum ve davranışlarını inceledikleri çalışmanın neticesinde ise, öğrencilerin çevreye karşı tutum ve davranışlarında çevre eğitimi dersini aldıktan sonra olumlu yönde değişmeler olduğu ifade edilmiştir.

Öğretmen adaylarının çevresel davranış ölçeği puanlarının analizi adayların davranış ölçeği puanlarının cinsiyetlerine göre farklılaşmadığını göstermektedir ( $p>0,05)$ (Tablo.3). Elde edilen bu bulgu sorumlu çevresel davranışların cinsiyete göre farklılaştığını gösteren çalışma bulgularıyla (Willuweit, 2009; Timur v.d., 2012; Güler, 2013; Malhotra and Chabra, 2014) çelişmekle beraber sorumlu 
çevresel davranışların cinsiyete göre farklılaşmadığını gösteren benzer araştırma sonuçlarıyla örtüşmektedir (Budak et al., 2005; Erdoğan, 2011; Altınöz, 2010; Karatekin, 2011; Gürbüz ve Çakmak, 2012; Timur v.d., 2013). Böyle bir sonucun ortaya çıkmasında çevre sorunlarının cinsiyet farkı gözetmeksizin bütün insanları olumsuz yönde etkileyen bir özelliğe sahip olmasının etkili olabileceği düşünülmektedir. Nitekim Erten (2004)'e göre çevre sorunları lokal değil global bir sorundur ve "çevre sorunları din, dil, ırk, yaşlı-genç, kadın-erkek, zengin-fakir, akademisyen-çiftçi, köylü-şehirli, fen bilgisi veya müzik öğretmeni, matematik, kimya veya fizik öğretmeni gibi bir ayrıma gitmeden herkesi etkiler." (Erten, 2004:3).

Öğretmen adaylarının çevresel kuruluşlara üyeliklerinin çevresel davranışları üzerinde etkisini belirlemeye yönelik olarak yapılan analizler çevre kuruluşlarına üyeliğin öğretmen adaylarının çevresel davranışları üzerinde herhangi bir etkisinin olmadığını göstermektedir $(\mathrm{p}>0,05)$ (Tablo.4). Bu sonucun ortaya çıkmasında herhangi bir çevre kuruluşuna üye olduğunu belirten öğretmen adaylarının sayısının azlığının etkili olduğu düşünülmektedir. Gürbüz ve Çakmak (2012) tarafından yapılan benzer bir çalışmada da öğretmen adaylarının yalnızca \%16'sı çevreyle ilgili bir birime üye olduğunu belirtmiştir. Uzun ve Sağlam (2007) ise ortaöğretim öğrencilerinin çevreyle ilgili bilgi ve tutumlarına çevre ve insan dersi ile gönüllü çevre kuruluşlarının etkisini inceledikleri çalışmalarında gönüllü çevre kuruluşlarına üye olup çalışmalarına aktif olarak katılan öğrencilerin sayısının oldukça az olmakla birlikte bu öğrencilerin çevresel bilgi, davranış ve düşünce puan ortalamalarının üye olmayanlara göre yüksek olduğunu ancak bu sonucun istatistiksel olarak anlamlı olmadığını ifade etmişlerdir.

Yapılan istatistiksel analiz sonuçları, resmi kurumlar tarafından düzenlenen çevresel etkinliklere katılan öğretmen adaylarının ölçek puanı ortalamalarının, bu etkinliklere katılmayan öğretmen adaylarının ölçek puanı ortalamalarından istatistiksel olarak daha yüksek olduğunu göstermektedir $(p<0,05)$ (Tablo.5). Elde edilen bu bulgu doğa eğitimi programlarının öğrencilerin çevreyle ilgili davranışlarına önemli ölçüde etki ettiğini gösteren araştırma bulgularıyla benzerlik göstermektedir (Keleş v.d., 2010; Özdemir, 2010; Erdoğan, 2011). Bu bulgunun elde edilmesinde düzenlenen eğitim programlarında uygulanan aktif öğrenme yöntem ve teknikleriyle (Keleş v.d., 
2010) doğal alanlarda yapılan uygulamaların (Erdoğan, 2011) etkili olabileceği düşünülmektedir.

Araştırmaya katılan öğretmen adaylarının davranış ölçeği puanlarının anabilim dalı analizi sonuçları öğretmen adaylarının davranış ölçeği puanlarının öğrenim gördükleri anabilim dallarına göre farklılaşmadığını göstermektedir ( $p>0,05$ ) (Tablo.6 ve 7). Polat (2012) eğitim fakültesinde bulunan bazı ögretmen yetiştirme programlarında öğrenim görmekte olan öğretmen adaylarının çevre sorunlarına yönelik tutumlarını farklı değişkenler açısından analiz etmiş ve adayların çevre sorunlarına yönelik tutumlarının öğrenim gördükleri lisans programına göre farklılaşmadığını belirlemiştir. Benzer şekilde Ercengiz v.d. (2014) de yapmış oldukları çalışmalarında öğretmen adaylarının çevre sorunlarına yönelik duyarlılıklarının öğrenim gördükleri lisans programlarına göre farklılaşmadığını ifade etmişlerdir. Bu sonucun ortaya çıkmasında da, çalışmamızın sonuç ve tartışma kısmının ikinci paragrafında belirtildiği üzere, çevre sorunlarının toplumun tüm kesimini etkileyen küresel özelliğinin etkili olduğu (Erten, 2004) düşünülmektedir.

Araştırma verilerinin birinci ve dördüncü sınıfta öğrenim gören öğretmen adaylarının davranış ölçeği puanları arasında dördüncü sınıfta okuyan öğretmen adaylarının lehine istatistiksel olarak anlamlı bir farklılık olduğunu göstermektedir $(\mathrm{p}<0,05)$ (Tablo.8). Çimen v.d. (2011)'nin biyoloji öğretmeni adaylarının çevreye duyarlı davranışlarını inceledikleri çalışmalarında öğretmen adaylarının çevreye duyarlı davranışlarının sınıf değişkenine göre farklılaştı̆̆ı, birinci ve dördüncü sınıf öğretmen adayları arasında dördüncü sınıfta okuyan öğretmen adayları lehine anlamlı bir farklılık olduğu ifade edilmiştir. Eğitim düzeyinin çevreye duyarlı davranışlara etkisi göz önüne alındığında (Easton et al., 2009) elde edilen bu bulgu beklenen bir sonuç olarak değerlendirilmektedir. Bununla birlikte birinci ve dördüncü sınıfta okuyan öğretmen adaylarının davranış ölçeği puanları arasında belirlenen farkın anabilim dallarına ait analiz sonuçları ise yalnızca fen bilgisi öğretmenliği anabilim dalı dördüncü sınıfında okuyan öğretmen adaylarının davranış ölçeği puan ortalamalarındaki artışın istatistiksel olarak anlamlı olduğunu göstermektedir $(p<0,05)$ (Tablo.9). Bu sonuç Timur v.d. (2013) tarafından yapılan ve fen bilgisi öğretmen adaylarının çevre davranış ölçeği puanlarının diğer anabilim dallarında öğrenim görmekte olan öğretmen adaylarının ölçek 
puanlarından daha yüksek olduğunu gösteren araştırma bulgusuyla örtüşmektedir. Belirlenen bu farklılık anabilim dallarındaki çevreyle ilgili ders sayısından kaynaklanıyor olabilir. Her üç anabilim dalının da müfredat dersleri incelendiğinde, seçmeli dersler hariç tutulacak olursa, fen bilgisi öğretmenliği anabilim dalındaki çevre ve çevre sorunları ile ilgili ders sayısının diğer iki anabilim dalından daha fazla olduğu görülmektedir.

Çalışma neticesinde elde edilen bulgular 1şığında aşağıdaki önerilerin dikkate alınmasının faydalı olabileceği düşünülmektedir:

1. Öğretmen adaylarının çevre ile ilgili resmi ve yasal kuruluşlara üyelikleri artırılmalıdır.

2. Bu kuruluşlarla işbirliği yapılıp kuruluşların öğretmen adaylarına tanıtılması sağlanmalıdır.

3. Çevre ile ilgili resmi ve yasal kuruluşlarca desteklenen etkinliklerin sayısı artırılmalı ve öğretmen adaylarının bu etkinliklere katılımı sağlanmalıdır.

4. Öğretmenlik lisans programlarındaki çevre ile ilgili ders sayısı artırılmalıdır.

\section{Kaynaklar}

Akıllı, M. ve Yurtcan, M.T. (2009). İlköğretim fen bilgisi öğretmeni adaylarının çevreye karşı tutumlarının farklı değişkenler açısından incelenmesi (Kazım Karabekir Eğitim Fakültesi Örneği). Erzincan Eğitim Fakültesi Dergisi, 11(2), 119-131.

Altınöz, N. (2010). Fen bilgisi öğretmen adaylarının çevre okuryazarlı düzeyleri. Yayımlanmamış Yüksek Lisans Tezi, Sakarya Üniversitesi, Fen Bilimleri Enstitüsü, Sakarya.

Bener, Ö., Babaoğul, M. (2008). Sürdürülebilir tüketim davranışı ve çevre bilinci oluşturmada bir araç olarak tüketici eğitimi. Hacettepe Üniversitesi Sosyolojik Araştırmalar E-dergisi, 20.09.2015 tarihinde http://www.sdergi.hacettepe.edu.tr/makaleler/surdurulebilirtuketimdavranis i.pdf adresinden alınmıştır.

Budak, D.B., Budak, F., Zaimoğlu, Z., Kekeç, S. ve Sucu, M.Y. (2005). Behaviour and attitudes of students towards environmental issues at faculty of agriculture, Turkey. Journal of Applied Sciences, 5(7), 1224-1227. 
M.Kışoğlu,T.Yıldırım... /Ë̈ Ĕ̆itim Fakültesi Dergisi, 18-1(2016),299-318

Çimen, O., Yılmaz, M. ve Çimen, G. (2011). Biyoloji öğretmen adaylarının çevre duyarlı davranışlarının çeşitli değişkenlere göre incelenmesi. Selçuk Üniversitesi Ahmet Keleşoğlu Eğitim Fakültesi Dergisi, Sayı:32, 191-201.

Disinger, J.F. (1982). Environmental education research news. The Environmentalist, 2, 285-288.

Easton, J., Lujenberg, M.K ve Cheng, J. (2009). Discourses of pro-environmental behavior: experiences of graduate students in conservation-related disciplines. Applied Environmental Education \& Communication, 8 (2), 126134.

Eilam, E. ve Trop, T. (2012). Environmental attitudes and environmental behaviorWhich is the horse and which is the cart?. Sustainability, 4, 2210-2246.

Ercengiz, M., Keçeci Kurt, S. ve Polat, S. (2014). Öğretmen adaylarının çevre sorunlarına yönelik duyarlılıklarının incelenmesi (Ağrı ili örneği). EKEV Akademi Dergisi, Y11:18, Say1:59, 119-132.

Erdoğan, M. (2011). Ekoloji temelli yaz doğa eğitimi programının ilköğretim öğrencilerinin çevreye yönelik bilgi, duyuşsal eğilimler ve sorumlu davranışlarına etkisi. Kuram ve Uygulamada Eğitim Bilimleri, 11(4), 22232237.

Erökten, S. ve Durkan, N. (2010). Çevre eğitimi dersinin öğrencilerin çevreye karş1 tutumları ve davranışları üzerine etkileri. E-Journal of New World Science Academy, 5(4), 1861-1867.

Erten, S. (2004). Çevre eğitimi ve çevre bilinci nedir, çevre eğitimi nasıl olmalıdır?, Çevre ve Insan Dergisi, Çevre ve Orman Bakanlığı Yayın Organı. Sayı 65/66. 2006/25 Ankara, 1-13.

Goldman, D., Yavetz, B. ve Pe'er, S. (2006). Environmental literacy in teacher training in Israel: Environmental behavior of new students. The Journal of Environmental Education, 38(1), 3-22.

Gül, F. (2013). İnsan doğa ilişkisi bağlamında çevre sorunları ve felsefe. Pamukkale Üniversitesi Sosyal Bilimler Enstitüsü Dergisi, Say1:14, 17-21.

Güler, E. (2013). İlköğretim 8. sınıf öğrencilerinin çevre okuryazarlı̆̆ı düzeylerinin belirlenmesi ve öğrencilerin okuryazarlı̆̆ düzeylerinin çeşitli değgş̧kenler açısından incelenmesi. Yayımlanmamış Yüksek Lisans Tezi, Çukurova Üniversitesi, Sosyal Bilimler Enstitüsü, Adana. 
M.Kışoğlu,T.Yıldırım... /Ë̈ Ĕgitim Fakültesi Dergisi, 18-1(2016),299-318

Gürbüz, H. ve Çakmak, M. (2012). Biyoloji eğitimi bölümü öğrencilerinin çevreye yönelik tutumlarının incelenmesi. Dicle Üniversitesi Ziya Gökalp Ĕ̈itim Fakültesi Dergisi, 19, 162-173.

Güven, E. ve Aydoğdu, M. (2012). Çevre sorunlarına yönelik davranış ölçeğinin geliştirilmesi ve öğretmen adaylarının davranış düzeylerinin belirlenmesi. Uludağ Üniversitesi Eğitim Fakültesi Dergisi, 25(2), 573-589.

Kanyimba, A.T. (2014). Exploring Students' views on orientations of environmental education at the university of Namibia. Creative Education, 5, 552-563.

Karasar, N. (1994). Bilimsel Araştırma Yöntemi: Kavramlar, Illkeler, Teknikler. 3A Araştırma Eğitim Danışmanlık Ltd., Ankara.

Karatekin, K. (2011). Sosyal bilgiler ögretmen adaylarının çevre okuryazarlık düzeylerinin belirlenmesi. Yayımlanmamış Doktora Tezi, Gazi Üniversitesi, Eğitim Bilimleri Enstitüsü, Ankara.

Karatekin, K. (2013). Öğretmen adayları için katı atık ve geri dönüşüme yönelik tutum ölçeğinin geliştirilmesi: Geçerlik ve güvenirlik çalışması. Uluslar arası Avrasya Sosyal Bilimler Dergisi, 4(10), 71-90.

Keleş, Ö., Uzun, N. ve Varnacı Uzun, F. (2010). Öğretmen adaylarının çevre bilinci, çevresel tutum, düşünce ve davranışlarının doğa eğitimi projesine bağlı değişimi ve kalıcılığının değerlendirilmesi. Elektronik Sosyal Bilimler Dergisi, 32(9), 384-401.

Kimaryo, L.A. (2011). Integrating environmental education in primary school education in Tanzania teachers' perceptions and teaching practices. Finland: Abo Akademi University Press. 03.12.2015 tarihinde http://www.doria.fi/bitstream/handle/10024/67481/kimaryo_lydia.pdf adresinden alınmıştır.

Koç, H. ve Karatekin, K. (2013). Coğrafya öğretmen adaylarının çevre okuryazarlık düzeylerinin çeşitli değişkenler açısından incelenmesi. Marmara Coğrafya Dergisi, Say1:28, 139-174.

Malhotra, T. ve Chabra, S. (2014). A study of responsible behaviour among b.ed. distance learners with reference to their locality, gender, stream and socioeconomic status. International Women Online Journal of Distance Education, 3(2), 1-10.

Özdemir, O. (2010). Doğa deneyimine dayalı çevre eğitiminin ilköğretim öğrencilerinin çevrelerine yönelik algı ve davranışlarına etkisi. Pamukkale Üniversitesi Ĕgitim Fakültesi Dergisi, Say1:27, 125-138. 
M.Kışoğlu,T.Yıldırım... /Ë̈ Ĕ̆itim Fakültesi Dergisi, 18-1(2016),299-318

Pe'er, S., Goldman, D. ve Yavetz, B. (2007). Environmental literacy in teacher training: Attitudes, knowledge, and environmental behavior of beginning students. The Journal of Environmental Education, 39(1), 45-59.

Polat, S. (2012). Öğretmen adaylarının (sosyal bilgiler, fen bilgisi, ilkögrretim din kültürü ve ahlak bilgisi, Türkçe) çevre sorunlarına yönelik tutumları. Yayımlanmamış Yüksek Lisans Tezi, Erciyes Üniversitesi, Eğitim Bilimleri Enstitüsü, Kayseri.

Pooley, J.A. ve O'conner, M. (2000). Environmental education and attitudes emotions and beliefs are what is needed. Environment and Behavior, 32(5), 711-723.

Pradhan, R.K., Jena, L.K. ve Behera, B. (2015). Human behavior, environmental problem and social wellness: An interdisciplinary exploration. International Journal of Development and Sustainability, 4(3), 308-321.

Sadık, F. ve Çakan, H. (2010). Biyoloji bölümü öğrencilerinin çevre bilgisi ve çevre sorunlarına yönelik tutum düzeyleri. Ç.Ü. Sosyal Bilimler Enstitüsü Dergisi, 19(1), 351-365.

Said, A.M., Ahmadun, F.R., Paim, L.H. ve Masud, J. (2003). Environmental concerns, knowledge and practices gap among Malaysian teachers. International Journal of Sustainability in Higher Education, 4(4), 305-313.

Steg, L. ve Vlek, C. (2009). Encouraging pro-environmental behaviour: An integrative review research agenda. Journal of Environmental Psychology, 29, 309-317.

Swim, J.K., Clayton, S. ve Howard, G.S. (2011). Human behavioral contributions to climate change psychological and contextual drivers. American Psychologist, 66(4), 251-264.

Şimşekli, Y. (2004). Çevre bilincinin geliştirilmesine yönelik çevre eğitimi etkinliklerine ilköğretim okullarının duyarlılığı. Uludă̆ Üniversitesi Eğitim Fakültesi Dergisi, 17(1), 83-92.

Timur, S., Timur, B. ve Yılmaz, Ş. (2012). Fen ve teknoloji öğretmenleri ve öğretmen adaylarının çevreye yönelik davranışlarının incelenmesi. Gazi Üniversitesi Gazi Eğitim Fakültesi Dergisi, 32(3), 777-793.

Timur, S., Yılmaz, Ş. ve Timur, B. (2013). Öğretmen adaylarının çevreye yönelik davranışlarının incelenmesi. YYÜ Ĕ̆itim Fakültesi Dergisi, 10(1), 125-141. 
M.Kışoğlu,T.Yıldırım... /Ë̈ Ĕ̆itim Fakültesi Dergisi, 18-1(2016),299-318

Uzun, N. Ve Sağlam, N. (2007). Ortaöğretim öğrencilerinin çevreye yönelik bilgi ve tutumlarına "Çevre ve İnsan” dersi ile göneüllü çevre kuruluşlarının etkisi. Hacettepe Üniversitesi Ĕ̆itim Fakültesi Dergisi, 33, 210-218.

Vlek, C. ve Steg, L. (2007). Human behavior and environmental sustainability: Problems, driving forces, and research topics. Journal of Social Issues, 63(1), 1-19.

Willuweit, L. (2009). Promoting pro-environmental behavior an investigation of the cross-cultural environmental behavior patterns. The case of Abu Dhabi. Unpublished Master Thesis, Stockholm University, Department of Human Geography, Stockholm. Retrieved December 18, 2015 from https://www.diva-portal.org/smash/get/diva2:235822/FULLTEXT01.pdf

\section{Extended Summary}

The century we live in has become a period through which the effects of the environmental problems are increasingly experienced. The main cause of the environmental problems such as global warming, air pollution, noise and decrease of biodiversity is human behaviour. (Vlek and Steg, 2007). Reducing the negative effects of human behavior damaging the environment is possible by means of changing the current behavior of individuals (Steg and Vlek, 2009). Changing the behavior of individuals giving harm to the environment and achieving sensitive behavior towards the environment for individuals can be provided through an effective environmental education. The environmental programs in which the main purpose is to change the environmental behaviour by increasing environmental knowledge (Pooley and O'conner, 2000), set important tasks on the teachers who are the implementers of the program. As well as implementing environment programs, the teachers' positive behavior towards environment is being role model for their students in a positive manner in terms of environment. (Timur v.d.,2013)

\section{Purpose}

In this study, behavioral level of science, classroom and social science preservice teachers was aimed to examine in terms of different variables with regard to the environment problems when they start the service.

\section{Method}

This study is a descriptive study realized with screening method. The reason why the scan model is used in the research is that scan model is a model aiming to describe the current situation in the past or at present with the form of existing 
M.Kışoğlu,T.Yıldırım... /Ë̈ Ĕgitim Fakültesi Dergisi, 18-1(2016),299-318

without exposing any effect or change. (Karasar, 1994). The sample of the study constitutes 344 preservice teachers in the first and fourth class departments' of science, classroom and social sciences at an educational faculty of a university located in the Central Anatolia Region. The data of the study was collected through a questionnaire consisting of two parts. The first part of the questionnaire questions is located to determine the candidates' gender, the department and class in which they study, whether they are members of any environmental organization and whether they participate in any environmental events organized by public agencies such as science, camp, nature, education. In the second part of the questionnaire of Behavior Scale for Environmental Problems that had 40 items developed by Güven and Aydoğdu (2012) was used. The items located in the behavior scale prepared as six factors and three Likert type were created by taking into account of the steps of psychomotor areas in Bloom's Taxonomy. When the data of the study was encoded, the answers of the candidates did not accept in the scale were encoded as 1, indicating the neutral answer was encoded as 2 , the responses of the teachers represent to participate in were encoded as 3 . When the items that expressed negativity were encoded, they were inverted. Data was analyzed by using independent samples t-test and one way Anova in the SPSS 15.0 statistical software. In the statistical analyzes the level of significance was taken as (p) 0.5.

\section{Results}

As a result of the study the mean scores of the teacher candidates received from the behavior scale was found to be above the avarage score $(X=92,01)$ taken from the scale. The finding coincides with the results of the similar study Çimen et al. (2011) which shows that all have made shows the teacher candidates' environmentally behavior above the average.

According to the t-test analyze results indicating whether there is a difference in the behavior scale according to the gender, the average of behavior scale of the woman preservice teachers $(X=92,38)$ is higher than the average of the behavior scale of the man $(X=91,14)$ preservice teachers there is no statistically significant difference between scores by gender $(\mathrm{p}>0,05)$.

As the result of the series of analysis whether the memberships of the teacher candidates has an impact upon environmental behavior, the number of the teacher candidates that become a member of any environmental organization $(N$ $=20)$ is lower than the teacher candidates that don't become a member $(N=324)$. Despite this, the scale scores' average of the preservice teachers that have a membership to an environment organization $(X=94,25)$ is higher than the scale scores' average of the teacher candidates that don't have a membership $(X=91,87)$. The analyze results are made whether there is a meaningful difference showing between the behavior average of the teacher candidates that are the members and the preservice teachers that are not the member, there is not a meaningful difference ( $p>0.05)$.

According to the results of independent t-test analysis made to determine the difference between the teachers participate in the environment activities organized by official organizations and they do not participate in, the number of the pre- 
service teachers participate in environment activities organized by government agencies is lower $(N=80)$ than the number of the candidates do not participate $(N=264)$. However scale score averages of the preservice teachers $(X=93,99)$ that participate in the environmental activities organized by the government agencies are statistically higher than the scale score averages $(X=91,41)$ of the teacher candidates that do not participate in $(\mathrm{p}<0,05)$.

The one way variance analysis being made to determine whether there is a difference among the preservice teachers come from different departments shows no difference the average of the behavior scale scores that the preservice teachers got from according to the their departments they study. ( $p>0,05)$.

Whether there is a meaningful difference among the average scores of the preservice teachers studying in the first and the fourth classes was analyzed with the independent groups t-test, among the behavior scale scores of the preservice teachers studying at the first and fourth class, it was determined that there was a statistically meaningful difference in favor of the preservice teachers studying in the fourth class $(p<0,05)$. The identified difference according to the department results between the behavior scale score of the preservice teachers studying in the first and fourth class, the increase of the average behavior scale scores of the preservice teachers only studying at the fourth class of the science department was found statistically meaningful $(\mathrm{p}<0,05)$. The increase in between the behavior scale score of the social studies teaching and primary school teaching departments weren't statistically meaningful $(p>0,05)$. According to the results, these suggestions can be made:

1. Teacher candidates' membership of official and legal environmental organizations should be increased.

2. Environmental organizations should be introduced to teacher candidates in cooperation with these organizations.

3. The number of activities supported by official and legal environmental organizations should be increased. And, teacher candidates should be got involved in these activities.

4. The number of lessons about environment in teacher education programs should be increased. 